\title{
Predictors of boredom at lectures: Medical Students' experience
}

\author{
Josephine Nonye Ubah \\ College of Health Sciences, \\ Ladoke Akintola University of Technology, \\ Osogbo, Osun State, Nigeria
}

\begin{abstract}
Boredom is a negative experience common among students. Their attention need to be captivated for a reasonable length of time during lectures to grasp information being transmitted. Causes of boredom are many. Many ideas and activities have been suggested to cope with it. These include among others; reduction in the number of power point slides, introducing funny and interesting activities or sections and interacting with students one on one. The aim of this study was to identify the causes of boredom during lectures in a group of students in a medical school. There were 54 students consisting of 22 females and 32 males, with mean age of 27.39 (SD 2.978) years. The strongest predictors of boredom were prolonged lectures, organising lectures towards the end of the day, series of lectures without break and unconducive class rooms. Short span of attention and consuming large meals before lectures were not considered significant causes. The responses were similar in both sexes. Different causes of boredom have been identified. Lecturers should be conversant with these causes and introduce means to eliminate or reduce them to the barest minimum.
\end{abstract}

Keywords: Boredom, causes, lectures, medical students

\section{INRODUCTION}

Boredom is a negative emotional experience common among students [Mann 2009 \& Wiggins 2013]. It has been defined in Wikipedia [2017] as, "an emotional or psychological state experienced when an individual is left in his or her surroundings, or feels that a day or period is dull or tedious". Boredom leads to affectation of the cognitive ability of students. Students attention need to be captivated in the class for a reasonable length of time to grasp the information being passed across. Boredom could be caused by reduced attention span which is the amount of concentrated time one can spend on a task without becoming distracted. Boredom and attention span could affect one other. While boredom can reduce attention span, short attention span can cause boredom. Attention span could be as short as 8 seconds although it has been found that most teenagers and adults have span of about 20 minutes. However, in practice most lectures last for more than 20 minutes [Comish \& Dukette 2009].

Mann [2009] established that almost 60\% of the students they studied found at least half their lectures boring, and 30\% claiming to be bored by all the lectures. Lecture unfortunately is still the most common method of teaching because many students are reached at a time.

\section{Causes of boredom}

Causes of boredom could be classified under student, lecturer, institutional or subject related factors.

Student related causes could be short span of attention, distractions from home, ill health and tiredness. 
Lecturer oriented causes include the manner of transmitting information and mastery of the topic. Nature or content of the subject comes into play when the topic is naturally difficult. Institution could be responsible by fixing lectures at the end of the day or in unconducive classrooms.

\section{Strategies adopted by students to cope with boredom}

Boredom is an unpleasant experience which students try to eliminate by indulging in some activities like, daydreaming, chatting with friends, sending texts, passing notes or even leaving the lecture room [Mann 2009]. These actions impact negatively on students as they miss out on the information being passed across.

\section{Management of boredom}

To eliminate or reduce boredom, some authors have suggested reduction in the number of slides and amount of information in each slide, providing accompanying handouts and making the slides colourful [Mann 2009 \& Wiggins 2013].

Introducing funny sections or activities, one on one interaction with students, displaying videos, pictures and establishing friendly competitions among students by asking some interesting questions [Wiggins 2013] are other ways to cope with it.

Since the aim of teaching is to impact knowledge, and boredom is a phenomenon well known to and experienced by students, it is necessary to find out the causes of boredom among students. This present study was conducted to highlight the causes of boredom in a class of medical students.

\section{METHODS}

The study involved distribution of semi structured questionnaire to a group of medical students who just completed some lecture series and were judged most appropriate for the study. There were 54 students who gave their consent and completed the questionnaires. Uncompleted questionnaires were excluded from the study. The questionnaire had 13 questions and the students were to select one of the options: agree, strongly agree, not sure, disagree or strongly disagree for each question. There was also room to elaborate certain answers. The questions were designed to highlight one of the factors that could be responsible for boredom; teacher, student, institution or subject factors. Responses obtained were analysed using descriptive and chi square statistics with SPSS version 23.

\section{RESULTS}

There were 22 females and 32 males with age ranging from 21 to 38 years. The mean age was 27.39 (SD 2.978). The results obtained showed that there were no significant differences in the responses between the males and females. The various responses are shown in Table 1.

The strongest predictors of boredom were prolonged lectures in 51(94.4\%), organising lectures towards the end of the day in 50 (90.7\%), piling series of lectures without break in 50 $(90.7 \%)$ and unconducive class room like stuffy, hot classrooms in $49(83.3 \%)$ students. A great majority disagreed that use of power point was a cause of boredom 49(90.7\%). Few of them, $10(18.5 \%)$ agreed that short span of attention and taking large meals before lectures $20(37.0 \%)$ could be responsible. Further on the manners of lecture delivery, the points raised were; reading from the slides and texts without explanations and poor knowledge of the topic been taught. This makes lecturers avoid questions or become unapproachable. Other views were; poor audibility of the lecturer, not carrying students along; some are unfriendly and lack the ability to express themselves. 
Student factors identified were; ill health, dislike of the lecturer and emotional disturbances resulting from poor financial status, prolonged stay in medical school and eating large meals before lectures.

The maximum length of time suggested for lectures is depicted in figure 1. Majority of the students $23(42.6 \%)$ would not like lectures to exceed an hour at a stretch, and 2 hours at most in $18(33.3 \%)$.

\section{DISCUSSION}

According to Bennett [2013], students get bored when they have difficulty paying attention required for participating satisfactorily in an activity. Both teachers and students need to be familiar with the possible causes, and set machineries in place to eliminate or reduce it effectively because of its negative effects on education which could be damaging.

The current study has highlighted possible causes among the respondents.

Prolonged lectures was one of the commonest causes. Lectures could last for as long as one and half hours which is rather long, considering normal attention span of about 10 minutes Medina [2009]. In the present study, majority (42.6\%) of the students suggested one hour as the maximum length of time for a lecture. Individuals may listen for long periods if the topic is very easy to comprehend. Daschmann [2013] also reported prolonged lectures as a cause of boredom in her study. Breaking down lectures into shorter topics and introducing breaks in between can eliminate or reduce this factor.

Series of lectures without break was another common predictor. Possible reasons for this could be, an attempt to make up for lost time from whatever cause and large course content. Bansal [2016] made similar observation but pointed out that it depended on the teacher. He noted that with some professors, students never got bored. For listeners to pay attention during lectures for long periods of time without break, the topics would not only be interesting, the teacher must introduce some animations that will keep calling back the listeners' attention.

Giving lectures toward the end of the day was also a common cause identified in the present study. Towards the end of the day, both lecturers and students may be exhausted and hungry, and boredom could set in easily.

Most of the students disagreed that Power Point Presentation was responsible for boredom. Power point presentation offers a lot of advantages. It can use texts, photos, illustrations, movies, drawings, tables and graphs to effectively carry the audience along. It could also make presentations snappy. However, the result obtained was in disagreement with that of Mann [2009] and [Wiggins 2013] who reported it as one main contributor to boredom. In their reports, slides tended to be too many with too much information which students attempted to copy. Mann [2009] in addition, reported that movies were too long and teachers didn't seem to have interest in what they were teaching while Wiggins [2013] added that paragraphs were too many in a power point page.

Majority of the students made remarks on the manner some lecturers expressed themselves. They claimed that some lecturers; were not loud enough; did not carry the students along; avoided questions which was attributed this to none mastery of their topics; were not explanatory enough, rather unfriendly and harsh; read from prepared notes or power point without introduction of any sense of humour. These made mere sight of the lecturers boring. Some lecturers may not be aware that boredom is common among students and as a result, do 
not plan their presentations to minimize it. This is worse where the lecturer may not have had any form of training in education. This finding is similar to those of Daschmann [2013] and the suggestion of Patel [2013].

Forty nine $(90.7 \%)$ of the respondents agreed that unconducive classrooms could cause boredom. Classrooms that are stuffy and hot are uncomfortable and can impact negatively on both the learner and teacher. The class room is very important in the development of an individual. It has to be manipulated to promote learning and help the student thrive. Frosta [2013] and Ryann (2013) made similar observations.

Nature of topic was one of the factors also identified, in 39(72.2\%) of the students. Some topics are naturally uninteresting and difficult to understand because of the nature of the concepts. Daschmann 2013 also found that $69 \%$ of students in her study, were bored depending on the nature of the topic. Student familiarity with the concept being taught and absence from earlier lectures relating to same topic also contributed to boredom [Patel 2013].

Other less common causes of boredom highlighted in this study were; hunger, tiredness, prolonged stay in medical schools, not having enough sleep at night, emotional problems and eating large meals before lectures. This was Frosta's [2013] observation as well. Poor sleep at night could cause tiredness and irritation during the day resulting to loss of attention. Other predictors of boredom by Daschmann [2013] were, monotonous scheme in as much as $91 \%$ of students and students being in bad mood.

Except lectures are very interesting, the listener will be distracted. Good planning can help reduce many of these.

\section{CONCLUSION}

Many factors encompassing student, teacher, institutional and nature of the topic have been identified as causes of boredom in this study. All stake holders including institutional heads and administrators need to be well informed on these. Collective effort is needed to eliminate or reduce these factors. Lecturers should make lectures as interesting as possible. There is need to revise the topics ahead of each lecture, introduce some interesting sections during lectures and avoid prolonged lectures. Institutions should endeavour to create conducive classrooms and avoid fixing lectures towards the end of the day when tiredness begins to set in. Power point presentation is advocated in this study but the slides should not be packed with too much information. Students also have a part to play in taking care of this problem by making effort to avoid student related factors.

\section{References}

Bansal C (2016). In IIT can we get bored of lectures without break? Available:www.quora.com/In-IIT-can-we-getbored-of-lectures-without-a-break: (18, October 2017)

Bennett P. [2013]. Boredom in the classroom: Why are so many students bored and what can be done? Available http://educhatter.wordpress.com (December 18, 2017).

Comish D., Dukette D. [2009]. The Essential 20: Twenty components of Excellent Health Care Team. Pittsburgh, PA: Rose Dog Books. Pp72-73. ISBN 1-4349-9555-0. OCLC721335045.

Daschmann E. C. [2013]. Boredom in School from the Perspectives of Students, Teachers, and Parents. (PhD Dissertation). Konstanz, Germany.

Frosta R. [2013]. Why do we feel sleepy during lectures? Quora. Available: www.quora.com (December 2, 2017).

Mann S. [2009]. Why do $60 \%$ of students find their lectures boring? The guardian news. Available www.theguardian.com (May 31, 2017). 
Medina J. [2009]. People don't pay attention to boring things in : Brain rules, rule 4. Available: www.brainrules.net/pdf/brain rules-summaries.pdf (December 3, 2017).

Patel A. [2013]. Why do we feel sleepy during lectures? Quora. Available: www.quora.com (December 3, 2017).

Ryan H. [2013]. The effect of classroom environment on student learning. Honors Theses. Paper 2375.

Wiggins G. [2013]. Attention, Teachers! Why students are bored? Available: www.huffingtonpost.com (May 31, 2017).

Wikipedia. Boredom. Available: https://en,wikipedia.org/wiki/Boredom (May 15, 2017).

TABLES

Table 1: Response to possible predictors of boredom

\begin{tabular}{|l|l|l|l|l|}
\hline & Question & $\begin{array}{l}\text { Agree } \\
\text { Frequency(\%) }\end{array}$ & $\begin{array}{l}\text { Disagree } \\
\text { Frequency(\%) }\end{array}$ & $\begin{array}{l}\text { Not sure } \\
\text { Frequency(\%) }\end{array}$ \\
\hline 1 & Use of power point for teaching & $3(5.6)$ & $49(90.7)$ & $2(3.7)$ \\
\hline 2 & $\begin{array}{l}\text { The manner the lecturer expresses } \\
\text { himself }\end{array}$ & $41(75.9)$ & $7(13.0)$ & $6(11.1)$ \\
\hline 3 & Absence of power point & $42(77.8)$ & $7(13.0)$ & $5(9.3)$ \\
\hline 4 & Lecturer reading from written text & $38(70.4)$ & $12(22.2)$ & $4(7.4)$ \\
\hline 5 & Student having short span of attention & $10(18.5)$ & $27(50.0)$ & $17(31.5)$ \\
\hline 6 & Eating large meals before lectures & $20(37.0)$ & $21(38.9)$ & $13(24.1)$ \\
\hline 7 & Not having enough sleep at night & $45(83.3)$ & $6(11.1)$ & $3(5.6)$ \\
\hline 8 & Prolonged lectures & $51(94.4)$ & $2(3.7)$ & $1(1.9)$ \\
\hline 9 & Nature of the topic & $39(72.2)$ & $8(14.8)$ & $7(13.0)$ \\
\hline 10 & Lectures towards the end of the day & $50(92.6)$ & $3(5.6)$ & $1(1.9)$ \\
\hline 11 & Hot or stuffy class rooms & $49(90.7)$ & $1(1.9)$ & $4(7.4)$ \\
\hline 12 & Lectures full of written texts without & $44(81.5)$ & $5(9.3)$ & $5(9.3)$ \\
\hline 13 & Series of lectures without break & $50(92.6)$ & $1(1.9)$ & $3(5.6)$ \\
\hline
\end{tabular}

\section{FIGURES}

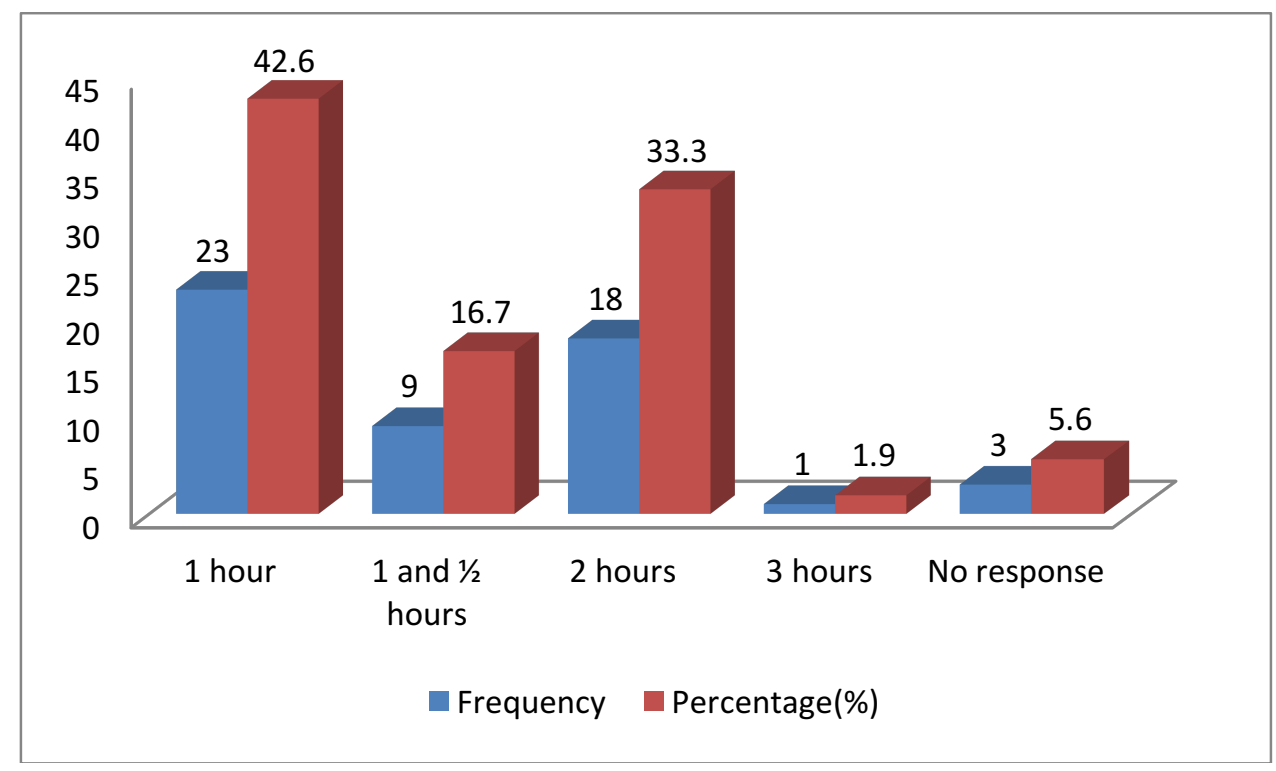

Figure 1. Maximum lecture duration suggested by the students 